\title{
PENELITIAN "RUBBER BLEND” ANTARA KARET ALAM RSS DENGAN KARET SINTETIS JSR 0061 UNTUK SOL RINGAN SESUAI SNI 12-0778-1989
}

\author{
Oleh : Penny Setyowati, Murwati, Sri Nadilah
}

\section{ABSTRACT}

The objective of this Research is to find composision of rubber blend of RSS and JSR 0061 and Carbon black for preparation light rubber sole compound and stabile on high process temperature that give the best fisical properties and the best sole product at moulding vulcanization trial. The best rubber compound to be reached at the compound formulation $R I I I$ with composision of RSS 90 phr, JSR 006110 phr and carbon black 40 phr.

\section{INTISARI}

Tujuan dari penelitian ini adalah mendapatkan komposisi campuran karet alam RSS dan karet sintetis JSR 0061 serta carbon black, untuk pembuatan kompon karet sol ringan dan stabil pada suhu proses tinggi yang memberikan sifat-sifat fisika terbaik serta menghasilkan produk sol yang terbaik pada uji coba cetak vulkanisasi. Kompon karet terbaik dicapa pada formulasi kompon R III dengan komposisi RSS 90 phr. JSR 006110 phr dan carbon black 40 phr.

\section{PENDAHULUAN}

Sejalan dengan program pemerintah dalam usaha meningkatkan pengembangan industri karet khususnya industri pengolahan barang karet yang ditekankan untuk memenuhi kebutuhan barang-barang karet didalam negeri dan kebutuhan eksport, maka perlu adanya usaha peningkatan kualitas produk atau barang jadi karet melalui optimalisasi penggunaan bahan baku dan bahan penolong yang sudah ada dipasaran Indonesia.

Sebagai contoh, dari segi kualitas, sol karet dituntut mempunyai sifat fisis kuat, lentur dan ringan. Untuk memperoleh sifat-sifat fisis yang diinginkan tersebut, harus didukung oleh penggunaan bahan baku dan bahan penolong yang memadai.

Untuk memperbaiki dan meningkatkan sifat-sifat fisis dari bahan karet dapat dilakukan penggabungan dengan karet jenis lain misalnya "Cold High Styrene Rubber" yang mempunyai sifat stabil dalam penyimpanan, kekerasan tinggi, density rendah, tahan kikisan dan tahan suhu tinggi. Sehubungan dengan hal tersebut, ada pemikiran untuk menggunakan campuran karet alam dengan styrene rubber JSR 0061 dalam pembuatan kompon sol karet yang bersifat keras, ringan dan tahan suhu proses tinggi. Dengan demikian proses cetak vulkanisasinya dapat dilakukan 
pada suhu tinggi dengan waktu relatif singkat tanpa berakibat penurunan sifatsifat fisikanya. Selain itu penggunaan "carbon black" sebagai "reinforcing filler" juga dapat dikurangi jumlahnya.

Tujuan dari penelitian ini adalah mendapatkan komposisi campuran karet alam (RSS) dan JSR 0061 serta penggunaan carbon black yang optimum dalam pembuatan kompon karet untuk sol khususnya untuk sol sepatu yang memerlukan sifat kekerasan tinggi, density rendah, tahan kikisan dan tahan suhu tinggi misalnya untuk sepatu militer.

Pada penelitian ini gabungan antara karet alam (RSS) dengan High Styrene Rubber JSR 0061 merupakan jenis "karet termoplastik stirenik", JSR 0061 berfungsi sebagai segmen keras (stiren) dan karet alam berfungsi sebagai segmen lunak (isoprena). Jenis karet termoplastik ini banyak digunakan untuk sol sepatu, terutama karena sifatnya yang tahan terhadap abrasi dan "fatique". Pada temperatur kamar jenis karet ini keras, karena setiap segmen lunak dikunci oleh segmen keras dan bersifat termoplastik karena akan menjadi lunak bila dipanaskan.

High Styrene Rubber JSR 0061 produksi Japan Synthetic Rubber Co.Ltd merupakan jenis karet dingin tipe non staining, yang dalam penerapannya dapat dicampurkan (di-blend) dengan karet lain misalnya SBR dan atau karet alam. Dalam hal ini dapat juga memperbaiki sifat-sifatnya antara lain dalam proses komponding, proses kalendering dan ekstrusi. Kelebihan dari JSR 0061 adalah dapat memberikan kekerasan tinggi dengan density rendah, mempunyai ketahanan kikis yang bagus, serta memberikan ketahanan sobek dan bekukan yang tinggi sifat ini cocok untuk kebutuhan sol sepatu militer.

\section{MATERI DAN METODE PENELITIAN}

\section{MATERI PENELITIAN}

\subsection{Bahan}

RSS I, JSR 0061, ZnO, Asam stearat, HAF Black, Silika, Coumaron resin, Napthanic oil, Pilnox TDQ, Dispergator FL, Pilgard PVI, Pilflex IP, MBT, MBTS, TMT dan Sulfur.

\subsection{Alat}

Mesin Two roll mill, Neraca, Hydrolic press, Tensile Strength Machine, Hardness tester, Abrasion tester, Permanent set tester, Flexing tester, dan Direct molding machine.

\section{METODE PENELITIAN}

\subsection{Formulasi Kompon}

Pada tahap ini dilakukan pembuatan kompon dengan 3 (tiga) formulasi yaitu dengan variasi komposisi campuran karet alam (RSS) dan JSR 0061 serta jumlah carbon black sebagai berikut (tabel.1)

Tabel 1. Formulasi kompon karet sol sepatu

\begin{tabular}{|c|c|c|c|c|}
\hline No. & Bahan & $\begin{array}{c}\text { Formulasi I } \\
\text { R I (phr) }\end{array}$ & $\begin{array}{c}\text { Formulasi II } \\
\text { R II (phr) }\end{array}$ & $\begin{array}{c}\text { Formulasi III } \\
\text { R III (phr) }\end{array}$ \\
\hline 1. & RSS I & 70 & 80 & 90 \\
\hline 2. & JSR 0061 & 30 & 20 & 10 \\
\hline 3. & $\mathrm{ZnO}$ & 5 & 5 & 5 \\
\hline 4. & Asam Stearat & 1,5 & 1,5 & 1,5 \\
\hline 5. & Carbon Black HAF & 20 & 30 & 40 \\
\hline 6. & Silica & 20 & 20 & 20 \\
\hline 7. & Coumaron Resin & 5 & 5 & 5 \\
\hline 8. & Napthenic Oil & 8 & 8 & 8 \\
\hline 9. & Pilnox TDQ & 1 & 1 & 1 \\
\hline 10. & MBT & 0,7 & 0,7 & 0,7 \\
\hline 11. & MBTS & 0,7 & 0,7 & 0,7 \\
\hline 12. & TMT & 1 & 1 & 1 \\
\hline 13. & Dispergator $\mathrm{FL}$ & 1 & 1 & 1 \\
\hline 14. & Pilgard PVI & 0,2 & 0,2 & 0,2 \\
\hline 15. & Pilflex IP & 2 & 2 & 2 \\
\hline 16. & Sulfur & 2,5 & 2,5 & 2,5 \\
\hline
\end{tabular}

Urutan Pencampuran (Komponding) yang dinilai cukup efisien serta menghasilkan kompon yang cukup homogen adalah sebagai berikut :

a. JSR 0061 dimastikasi (digiling) dalam two roll mill sampai lumat dan menyatu, kemudian dikeluarkan dari two roll mill.

b. RSS dimastikasi tersendiri sampai cukup lunak, kemudian berturut-turut dimasukkan Pilnox TDQ, JSR 0061 yang sudah lumat, Dispergator FL, $\mathrm{ZnO}$, Asam stearat, Pilgard PVI, Pilflex IP dan setiap kali pemasukan bahan aditip, campuran perlu digiling beberapa saat supaya homogen.

c. Silica dan setengah dari carbon black dimasukkan berturut-turut sambil terus digiling, kemudiaan setengah carbon black sisanya dan napthenic oil dimasukkan

Vol. XII No. 24 Th. $1996 / 1997$ 
selang seling sampai seluruhnya masuk dan tercampur rata.

d. "Curing agent" MBT, MBTS, dan TMT dimasukkan serta terakhir sulfur, kemudian digiling beberapa saat dan kompon siap dikeluarkan dari two roll mill.

\subsection{Pengujian}

Kompon hasil penelitian R I, R II, dan R III diuji sifat fisisnya meliputi : Uji Tegangan Putus, Perpanjangan Putus, Kekerasan, Ketahanan Sobek, Bobot Jenis, Ketahanan Kikis, Perpanjangan Tetap $50 \%$ dan Uji Ketahanan Retak-lentur 150 kcs.

\subsection{Uji Coba Vulkanisasi}

Kompon hasil penelitian R I, R II dan R III dicoba dicetak vulkanisas menjadi sol sepatu pada kondisi suhu $165^{\circ} \mathrm{C}-17^{\circ} \mathrm{C}$, selama $7-8$ menit pada tekanan $150 \mathrm{~kg} / \mathrm{cm} 2$.

\subsection{Evaluasi}

Untuk menentukan formulasi kompon yang terbaik dalam arti mempunyai nilai uji fisis tertinggi serta dapat diproses cetak pada kondisi vulkanisasi yang sudah ditentukan dan menghasilkan vulkanisat yang baik, maka dilakukan evaluas secara statistik dengan jalan membandingkan ketiga hasil uji fisis untuk masingmasing jenis uji melalui analisa varian serta ditinjau pula "Hasil Pengamatan Proses Uji Coba Cetak Vulakanisasi”. Selanjutnya formulasi kompon yang terbaik dibandingkan dengan tolok ukur SNI 12-0778-1989 "Sol Karet Cetak"

\section{HASIL PENELITIAN DAN PEMBAHASAN}

Hasil penelitian terdiri dari hasil uji sifat fisis masing-masing kompon formula R I, R II dan R III disajikan pada tabel 2. , tabel 3. dan tabel 4.

Analisa statistik untuk menentukan formulasi yang terbaik dan rekapitulasi perhitungannya disajikan pada tabel 5 . Formulasi yang terbaik dibandingkan dengan tolok ukur SNI 12-0778-1989 "Sol Karet Cetak" disajikan pada tabel 6. serta "Hasil Pengamatan Proses Uji Coba Cetak Vulkanisasi" terhadap kompon formulasi R I, R II dan R III disajikan pada tabel 7.

\section{Tabel 2. Hasil Uji Fisis Kompon Karet Formulasi R I}

\begin{tabular}{|c|c|c|c|c|c|c|c|c|}
\hline \multirow[t]{2}{*}{ No } & \multirow[t]{2}{*}{ Jenis Uji } & \multirow[t]{2}{*}{ Satuan } & \multicolumn{5}{|c|}{ Hasil Uji Kompon R I } & \multirow{2}{*}{$\begin{array}{l}\text { Rata- } \\
\text { Rata }\end{array}$} \\
\hline & & & 1 & 2 & 3 & 4 & 5 & \\
\hline 1. & Tegangan Putus & $\mathrm{kg} / \mathrm{cm}^{2}$ & 134 & 137 & 142 & 141 & 137 & 138,2 \\
\hline 2. & Perpanjangan Putus, & $\%$ & 220 & 232 & 220 & 260 & 236 & 233,6 \\
\hline 3. & Kekerasan Shore A & - & 79 & 79 & 79 & 79 & 79 & 79 \\
\hline 4. & Ketahanan Sobek & $\mathrm{kg} / \mathrm{cm}^{2}$ & 62 & 61 & 60 & 68 & 61 & 62,4 \\
\hline 5. & Perpanjangan tetap $50 \%$, & $\%$ & 17 & 18 & 17,6 & 16 & 18 & 17,32 \\
\hline 6. & Bobot Jenis & $\mathrm{gt} / \mathrm{cm}^{3}$ & 1,13 & 1,13 & 1,04 & 1,08 & 1,14 & 1,10 \\
\hline 7. & Ketahanan Kikismm & $3 / \mathrm{kgm}$ & 1,5 & 1,56 & 1,28 & 1,40 & 1,52 & 1,45 \\
\hline 8. & Ketahanan Retak- & & tidak & tidak & tidak & tidak & retak & tidak \\
\hline & Lentur $150 \mathrm{kcs}$ & & retak & retak & retak & retak & tidak & retak \\
\hline
\end{tabular}

Tabel 3. Hasil Uji Fisis Kompon Karet Formulasi R II

\begin{tabular}{|c|c|c|c|c|c|c|c|c|}
\hline \multirow[t]{2}{*}{ No } & \multirow[t]{2}{*}{ Jenis Uji } & \multirow[t]{2}{*}{ Satuan } & \multicolumn{5}{|c|}{ Hasil Uji Kompon R II } & \multirow{2}{*}{$\begin{array}{l}\text { Rata- } \\
\text { Rata }\end{array}$} \\
\hline & & & 1 & 2 & 3 & 4 & 5 & \\
\hline i. & Tegangan Putus & $\mathrm{kg} / \mathrm{cm}^{2}$ & 160 & 159 & 159 & 161 & 145 & 156,8 \\
\hline 2. & Perpanjangan Putus, & $\%$ & 360 & 420 & 400 & 380 & 360 & 384 \\
\hline 3. & Kekerasan Shore A & - & 78 & 76 & 78 & 77 & 76 & 77 \\
\hline 4. & Ketahanan Sobek & $\mathrm{kg} / \mathrm{cm}^{2}$ & 65 & 70 & 72 & 69 & 67 & 68,6 \\
\hline 5. & Perpanjangan tetap $50 \%$, & $\%$ & 13 & 12,4 & 14 & 14 & 13 & 13,28 \\
\hline 6. & Bobot Jenis & $\mathrm{gr} / \mathrm{cm}^{3}$ & 1,15 & 1,04 & 1,12 & 1,12 & 1,06 & 1,10 \\
\hline 7. & Ketahanan Kikis & $\mathrm{mm}^{3} / \mathrm{kgm}$ & 1,46 & 1,27 & 1,28 & 1,39 & 1,47 & 1,37 \\
\hline 8. & Ketahanan Retak- & - & tidak & tidak & tidak & tidak & retak & tidak \\
\hline & Lentur $150 \mathrm{kcs}$ & & retak & retak & retak & retak & tidak & retak \\
\hline
\end{tabular}


Tabel 4. Hasil Uji Fisis Kompon Karet Formulasi R III

\begin{tabular}{|c|c|c|c|c|c|c|c|c|}
\hline \multirow[t]{2}{*}{ No } & \multirow[t]{2}{*}{ Jenis Uji } & \multirow[t]{2}{*}{ Satuan } & \multicolumn{5}{|c|}{ Hasil Uji Kompon R III } & \multirow{2}{*}{$\begin{array}{l}\text { Rata- } \\
\text { Rata }\end{array}$} \\
\hline & & & 1 & 2 & 3 & 4 & 5 & \\
\hline 1. & Tegangan Putus & $\mathrm{kg} / \mathrm{cm}^{2}$ & 163 & 161 & 158 & 160 & 172 & 162,8 \\
\hline 2. & Perpanjangan Putus, & $\%$ & 400 & 300 & 300 & 380 & 340 & 344 \\
\hline 3. & Kekerasan Shore A & - & 75 & 75 & 75 & 75 & 75 & 75 \\
\hline 4. & Ketahanan Sobek & $\mathrm{kg} / \mathrm{cm}^{2}$ & 107 & 124 & 125 & 117 & 135 & 121,6 \\
\hline 5. & Perpanjangan tetap $50 \%$, & $\%$ & 4,4 & 5,6 & 6,0 & 4,6 & 5,6 & 5,24 \\
\hline 6. & Bobot Jenis & $\mathrm{gr} / \mathrm{cm}^{3}$ & 1,14 & 1,01 & 1,12 & 1,08 & 1,13 & 1,10 \\
\hline 7. & Ketahanan Kikis & $\mathrm{mm}^{3} / \mathrm{kgm}$ & 1,03 & 1,07 & 1,02 & 0,96 & 1,0 & 1,02 \\
\hline 8. & Ketahanan Retak- & - & tidak & tidak & tidak & tidak & tidak & tidak \\
\hline & Lentur $150 \mathrm{kcs}$ & & retak & retak & retak & retak & retak & retak \\
\hline
\end{tabular}

Tabel 5. Rekapitulasi Perhitungan Statistik Metode CRD Untuk R.I, R.II, R.III

\begin{tabular}{|c|c|c|c|c|c|c|c|}
\hline \multirow[t]{2}{*}{ No } & \multirow[t]{2}{*}{ Jenis Uji } & \multicolumn{3}{|c|}{ Nilai Rata-rata } & \multirow{2}{*}{$\begin{array}{l}\text { Analisis of } \\
\text { Variance } \\
\text { (ANOVA) }\end{array}$} & \multirow{2}{*}{ LSD } & \multirow{2}{*}{$\begin{array}{l}\text { Keterang } \\
\text { an }\end{array}$} \\
\hline & & RI & RII & RIII & & & \\
\hline 1. & $\begin{array}{l}\text { Tegangan Putus } \\
(\mathrm{kg} / \mathrm{cm} 2)\end{array}$ & 138,2 & 159, & 162,8 & Beda Nyata & $\begin{array}{l}\mathrm{RI} \neq \mathrm{RII} \\
\mathrm{RI} \neq \mathrm{RIII} \\
\mathrm{RII} \sim \mathrm{RIII}\end{array}$ & $\begin{array}{l}\text { RIII } \\
\text { tertinggi }\end{array}$ \\
\hline 2. & $\begin{array}{l}\text { Perpanjangan Putus } \\
\text { (\%) }\end{array}$ & 233,6 & 384,0 & 344,0 & Beda Nyata & $\begin{array}{l}\mathrm{RI} \neq \mathrm{RII} \\
\mathrm{RI} \neq \mathrm{RIII} \\
\mathrm{RII} \sim \mathrm{RIII}\end{array}$ & $\begin{array}{l}\text { RII } \\
\text { Tertinggi } \\
\text { RII RIII }\end{array}$ \\
\hline 3. & Kekerasan Shore A & 79,0 & 77,0 & 75,0 & Beda nyata & $\begin{array}{l}\mathrm{RI} \neq \mathrm{RII} \\
\mathrm{RI} \neq \mathrm{RIII} \\
\mathrm{RII}\end{array}$ & $\begin{array}{l}\text { RI } \\
\text { tertinggi }\end{array}$ \\
\hline 4. & $\begin{array}{l}\text { Ketahanan Sobek } \\
\left(\mathrm{kg} / \mathrm{cm}^{2}\right)\end{array}$ & 62,4 & 68,6 & 121,6 & Beda nyata & $\begin{aligned} \mathrm{RI} & \neq \mathrm{RII} \\
\mathrm{RI} & \neq \mathrm{RIII} \\
\mathrm{RII} & \neq \mathrm{RIII}\end{aligned}$ & $\begin{array}{l}\text { RIII } \\
\text { tertinggi }\end{array}$ \\
\hline 5. & $\begin{array}{l}\text { Perpanjangan tetap } \\
50 \%(\%)\end{array}$ & 17,32 & 13,28 & 5,24 & Beda nyata & $\begin{array}{l}\mathrm{RI} \neq \mathrm{RII} \\
\mathrm{RI} \neq \mathrm{RIII} \\
\mathrm{RII} \neq \mathrm{RIII}\end{array}$ & $\begin{array}{l}\text { RIII } \\
\text { terbaik }\end{array}$ \\
\hline 6. & Bobot Jenis $\left(\mathrm{gr} / \mathrm{cm}^{3}\right)$ & 1.104 & 1,098 & 1,096 & Tidak beda & RI=RII $=$ RIII & - \\
\hline 7. & $\begin{array}{l}\text { Ketahanan Kikis } \\
\left(\mathrm{mm}^{3} / \mathrm{kgm}\right)\end{array}$ & 1,452 & 1,374 & 1,016 & Beda nyata & $\begin{array}{c}\mathrm{RI}=\mathrm{RII} \\
\mathrm{RI} \neq \mathrm{RIII} \\
\mathrm{RII} \neq \mathrm{RIII}\end{array}$ & $\begin{array}{l}\text { RIII } \\
\text { terbaik }\end{array}$ \\
\hline
\end{tabular}

Keterangan :

4 : berbeda nyata

- tidak berbeda nyata

= : sama dengan

Tabel 6. Nilai Rata-Rata Hasil Uji Fisika R III dibandingkan dengan Syarat Mutu SNI 12-0778-1989.

\begin{tabular}{|c|c|c|c|c|c|c|}
\hline \multirow[t]{2}{*}{ No } & \multirow[t]{2}{*}{ Jenis Uji } & \multirow[t]{2}{*}{ Satuan } & \multirow[t]{2}{*}{ R.III } & \multicolumn{3}{|c|}{ SNI 12-0778-1989 } \\
\hline & & & & A & B & C \\
\hline 1. & Tegangan Putus & $\mathrm{kg} / \mathrm{cm} 2$ & 162,8 & $\min .150$ & $\min .100$ & $\min .50$ \\
\hline 2. & Perpanjangan Putus, & $\%$ & 344,0 & $\min .250$ & $\min .150$ & $\min .100$ \\
\hline 3. & Kekerasan & Shore A & 75,0 & $55-80$ & $55-80$ & $55-80$ \\
\hline 4. & Ketahanan Sobek & $\mathrm{kg} / \mathrm{cm} 2$ & 121,6 & $\min 60$ & $\min 40$ & $\min .25$ \\
\hline \multirow[t]{2}{*}{5.} & Perpanjangan tetap & & & & & \\
\hline & $50 \%$ & $\%$ & 5,24 & maks. 4 & maks. 7 & maks. 10 \\
\hline 6. & Bobot Jenis & $\mathrm{gr} / \mathrm{cm} 3$ & 1,10 & maks.1,2 & maks.1,4 & maks.1,4 \\
\hline 7. & Ketahanan Kikis & $\mathrm{mm} 3 / \mathrm{kgm}$ & 1,02 & maks. 1 & maks. 1,5 & maks. 2,5 \\
\hline \multirow[t]{2}{*}{8.} & Ketahanan Retak- & - & tidak & tidak & tidak & tidak \\
\hline & Lentur $150 \mathrm{kcs}$ & & retak & retak & retak & retak \\
\hline
\end{tabular}

Tabel 7. Hasil Pengamatan Proses Uji Coba Cetak Vulkanisasi terhadap Kompon R.I, R.II, R.III.

\begin{tabular}{|l|l|l|l|l|}
\hline \multirow{2}{*}{ No. } & \multicolumn{1}{|c|}{ Pengamatan } & \multicolumn{3}{|c|}{ Hasil Pengamatan } \\
\cline { 3 - 5 } & \multicolumn{1}{|c|}{ R.I } & \multicolumn{1}{c|}{ R.II } & \multicolumn{1}{c|}{ R.III } \\
\hline 1. & $\begin{array}{l}\text { Perilaku kompon } \\
\text { selama proses } \\
\text { vulkanisasi }\end{array}$ & $\begin{array}{l}\text { Aliran (flow) dan } \\
\text { pengembangan kompon } \\
\text { terlalu cepat }\end{array}$ & $\begin{array}{l}\text { Aliran kompon dan } \\
\text { pengembangan ma- } \\
\text { sih agak cepat }\end{array}$ & $\begin{array}{l}\text { Aliran kompon nor } \\
\text { mal (pengembangan } \\
\text { normal). }\end{array}$ \\
\hline 2. & $\begin{array}{l}\text { Kenampakan vul- } \\
\text { kanisat hasil uji } \\
\text { coba cetak vulka- } \\
\text { nisasi berupa sol } \\
\text { karet cetak }\end{array}$ & $\begin{array}{l}\text { Bagian dalam berongga } \\
\text { (tidak penuh) sehingga } \\
\text { bagian tumit nampak } \\
\text { menggembung danba- } \\
\text { gian kembangan tidak } \\
\text { penuh }\end{array}$ & $\begin{array}{l}\text { Bagian dalam masih } \\
\text { agak berongga, } \\
\text { bagian tumit sedikit } \\
\text { menggembung dan } \\
\text { bagian kembangan } \\
\text { tidak penuh }\end{array}$ & $\begin{array}{l}\text { dan padat serta tumit } \\
\text { terlihat licin (tidak } \\
\text { meng gembung) dan } \\
\text { bagian kembangan } \\
\text { terisi penuh. }\end{array}$ \\
\hline
\end{tabular}


Dari tabel 5. terlihat bahwa :

a. Nilai tegangan putus yang tertinggi dicapai formulasi R III, hal ini disebabkan karena formulasi R III menggunakan campuran RSS yang tertinggi jumlahnya yaitu 90 phr, sehingga dapat memberikan sifat tegangan putus yang tinggi mengingat karet alam mempunyai sifat tegangan putus yang cukup baik.

b. Nilai Perpanjangan Putus terbaik dicapai pada formulasi R II, karena pada R II ini komposisi RSS sebanyak 80 phr dan JSR 0061 sebanyak 20 phr merupakan komposisi saling menguatkan sehingga vulkanisat mengalami perpanjangan yang lebih baik dan tidak mudah putus. Namun demikian secara statistik terbukti bahwa nilai perpanjangan putus R.II tidak berbedanyata dengan R.III

c. Formulasi R I memberikan nilai kekerasan tertinggi, hal ini disebabkan karena R I menggunakan komposisi JSR 0061 yang terbanyak yaitu 30 phr dan JSR 0061 merupakan segmen keras yang dapat memberikan kekerasan tinggi.

d. Nilai Ketahanan Sobek tertinggi dicapai pada formulasi R III yaitu pada komposisi RSS sebanyak 90 phr dan JSR 0061 sebanyak 10 phr yang merupakan komposisi dengan kandungan RSS tertinggi sehingga dapat memberikan sifat Ketahan Sobek yang tinggi mengingat sifat dari karet alam yang mempunyai Ketahanan Sobek cukup baik.

e. Formulasi R III memberikan nilai Perpanjangan tetap $50 \%$ yang terbaik yaitu $5,24 \%$, karena pada penggunaan JSR 0061 lebih dari 10 phr ternyata menghasilkan vulkanisat yang bersifat kurang elastis, mengingat sifat dari JSR 0061 yang keras dan kurang elastis.

f. Dari ketiga formulasi R I, R II dan R III, memberikan bobot jenis yang tidak berbeda dan nilainya cukup kecil yaitu sekitar $1,10 \mathrm{gr} / \mathrm{cm} 3$, sehingga bila dicetak menjadi barang jadi karet menghasilkan vulkanisat yang cukup ringan.

g. Ketahanan Kikis yang terbaik dicapai pada formulasi R III, karena gabungan antara karet alam sebanyak 90 phr dan JSR 0061 sebanyak 10 phr dapat memberikan Ketahanan Kikis yang baik mengingat karet alam sendiri mempunyai sifat tahan terhadap kikisan yang sangat baik.

Dengan memperhatikan hasil perhitungan statistik (tabel 5.), Hasil perbandingannya dengan syarat mutu SNI 12-0778-1989 (tabel 6.) dan "Hasil Pengamatan Proses Uji Coba Cetak Vulkanisasi” (tabel 7.) maka kompon formulasi R III merupakan formulasi yang terbaik dalam arti mempunyai sifat fisis yang tertinggi dan memenuhi persyaratan mutu SNI 12-0778-1989 "Sol Karet Cetak" serta dapat dicetak vulkanisasi yang menghasilkan vulkanisat cukup bagus, kematangan merata, padat (tidak ada gelembung), permukaan licin dan bagian kembangan terisi penuh.

\section{KISIMPULAN}

1. Formulasi kompon karet untuk sol yang mempunyai nilai uji fisika terbaik adalah formulasi R III, dengan komposisi RSS I 90 phr JSR $006110 \mathrm{phr}$ dan carbon black HAF 40 phr

2. Dari uji coba cetak vulkanisasi terhadap kompon karet R III menghasilkan sol yang keras, ringan dan diproses pada suhu $165^{\circ} \mathrm{C}-170^{\circ} \mathrm{C}$.

1. Kompon karet formulasi R III, memenuhi syarat mutu SNI 12-0778-1989.

\section{DAFTAR PUSTAKA}

1. DR.Ridha Arizal, MSc, "Dasar-dasar Pertimbangan Dalam Pemilihan Jenisjenis Karet Elastomer Untuk Pembuatan Barang Jadi Karet", Balai Penelitian Teknologi Karet, Bogor,1994.

2. DR.Ridha Arizal, MSc, "Pengetahuan Dasar Elastomer", Balai Penelitian Teknologi Karet, Bogor, 1994

3. Departemen Perindustrian,"SNI. 12-0778-1989 Karet Cetak" Tahun 1989.

4. Japan Synthetic Rubber, "JSR Polymer Data" Japan Synthetic Rubber Co.Ltd. 